\title{
A STUDY OF THERMAL DECOMPOSITION OF BROMOETHANE
}

\author{
Nicolas Vin, Frédérique Battin-Leclerc, Olivier Herbinet*, \\ Laboratoire Réactions et Génie des Procédés, CNRS, Université de Lorraine, BP 20451, 1 rue Grandville, \\ 54000 Nancy, France. \\ *Corresponding author: olivier.herbinet@univ-lorraine.fr
}

Published in the Journal of Analytical and Applied Pyrolysis

doi.org/10.1016/j.jaap.2018.10.005

\begin{abstract}
The pyrolysis of bromoethane under dilute atmosphere and quasi-atmospheric pressure was studied at temperatures from 600 to $975 \mathrm{~K}$ using a fused silica jet-stirred reactor (JSR) and an alumina tubular reactor (TR). In the JSR, a complete conversion was observed at a residence time of $2 \mathrm{~s}$, a temperature of $975 \mathrm{~K}$ and an inlet mole fraction of bromoethane of 0.01 . In the TR, the full conversion was observed from $925 \mathrm{~K}$. In both reactors, the following species were quantified: methane, ethylene, acetylene, ethane, 1,3butadiene, vinylacetylene and vinyl bromide. A new detailed kinetic model was developed and gave a good prediction for both reactors of the global reactivity and the major products. Flow rate and sensitivity analyses have been performed to better understand the important reaction pathways during bromoethane pyrolysis. They showed, in contrast to previous studies, that the radical mechanism is far from being negligible and that the sole analysis of reaction products can be misleading as the radical mechanism mainly lead to ethylene and $\mathrm{HBr}$ which are also the two products from the molecular decomposition reaction of bromoethane.
\end{abstract}

Keywords: bromoéthane; pyrolysis; molecular reaction; detailed kinetic modeling.

List of abbreviations: JSR: Jet-Stirred-Reactor; TR: Tubular Reactor; FTIR: Fourier Transform InfraRed Spectroscopy; GC: Gas Chromatography; GC-MS: Gas Chromatography - Mass Spectrometry; PFR: Plug Flow Reactor; Pe: Peclet criterion; J: Number of JSRs needed to assimilate our "PFR" as a cascade of JSRs; RTD: Residence Time Distribution; PSR: Perfectly-Stirred-Reactor; CSTR: Continous-Stirred-Tank-Reactor; 


\section{Introduction}

Brominated flame retardants (BFRs) has become of increasing concern to scientists because of their widespread use in large quantities in consumer products such like electronic devices (computers, televisions...) [1]. As a result, several BFRs were found in quantifiable levels in human bodys and many of these chemicals are now recognized as global contaminants and are associated with health effects [2]. The recycling of these electronic wastes by combustion requires a better knowledge about the thermal decomposition of BFRs and more generally about the brominated compounds [3], since the combustion and thermal decomposition of these compounds can lead to the formation of dioxin and furan like species [4]. Bromoethane $\left(\mathrm{C}_{2} \mathrm{H}_{5} \mathrm{Br}\right)$ is a haloalkane which could be used as a model molecule for aliphatic BFRs. This molecule is used for the production of other organic compounds by alkylation [5] and for the treatment of agricultural soils, by fumigation or the treatment of foodstuffs [6].

The pyrolysis of bromoethane was already investigated several times in literature. The first study was performed in 1931 by Lessig et al. [7] using a glass static vessel at temperatures between 573 and $673 \mathrm{~K}$. $\mathrm{HBr}$ and ethylene were identified as the main products and the existence of an unimolecular decomposition reaction was discussed:

$$
\mathrm{C}_{2} \mathrm{H}_{5} \mathrm{Br} \longrightarrow \mathrm{C}_{2} \mathrm{H}_{4}+\mathrm{HBr} \quad \text { (Reaction I) }
$$

Table 1 presents a summary of the previous studies of the thermal decomposition of bromoethane where the rate expression of reaction 1 was determined.

In 1933, Vernon et al. [8] have studied the thermal dissociation of bromoethane using a Pyrex vessel and proposed a first expression for the rate constant of reaction I at temperatures from 670 and $693 \mathrm{~K}$ and for pressures below 0.48 bar. Daniels et al. [9] in 1938 determined the rate expression of reaction I above 0.13 bar and for temperatures between 643 and $693 \mathrm{~K}$. At pressures below 0.13 bar, the value of the rate constant, $\mathrm{k}_{\mathrm{l}}$, decreased as the pressure decreased. Except ethylene and $\mathrm{HBr}$, the major products, the formation of small amounts of hydrogen, ethane, propane, butane was also observed in decreasing order of abundance. Authors also found that the addition of oxygen or bromine enhanced the decomposition of bromoethane, while the addition of NO has no influence on the reactivity. The effect of hydrogen and nitrogen addition on bromoethane pyrolysis has also been investigated by Fugassi et al. [15] in 1938 at 670 K. The addition of both additives led to a decrease of the reactivity. In 1952, Blades et al. [13] studied the decomposition of bromoethane in a tubular reactor with toluene as carrier gas to detect a free radical mechanism. Since no hydrogen, ethane or dibenzyl nor any products other than ethylene and $\mathrm{HBr}$ were 
found, they concluded to an only molecular mechanism. They measured a rate expression for reaction I at atmospheric pressure between 800 and 900 K. In 1956, Goldberg et al. [10] studied the kinetics of the pyrolysis of bromoethane in a batch reactor between 583 and $749 \mathrm{~K}$ and also determined the rate expression of reaction I. They reported that the over-all reaction is not a simple unimolecular reaction.

Table 1: Summary of conditions used in the previous studies of the thermal decomposition of bromoethane where a rate expression was measured for reaction I. Activation energies are in $\mathrm{kcal} / \mathrm{mol}$.

\begin{tabular}{ccccc}
\hline Instrument & Experimental Conditions & Bath gas & $k_{I}\left(\mathrm{~s}^{-1}\right)$ & Reference \\
\hline & $T=670-693 \mathrm{~K} ; 0.016<P<0.48 \mathrm{bar}$ & $/$ & $3.85 \times 10^{14} e^{-54.80 / R T}$ & Vernon et al., 1933 [8] \\
& $T=643-693 \mathrm{~K} ; P>0.13 \mathrm{bar}$ & $/$ & $1.16 \times 10^{14} e^{-53.80 / R T}$ & Daniels et al., 1938 [9] \\
Batch reactor & $T=653-703 \mathrm{~K} ; P=0.4 \mathrm{bar}$ & $/$ & $6 \times 10^{11} e^{-46.40 / R T}$ & Goldberg et al., 1956 [10] \\
& $T=653-703 \mathrm{~K} ; P=0.48 \mathrm{bar}$ & $/$ & $2.8 \times 10^{13} e^{-53.90 / R T}$ & Thomas et al., 1959 [11] \\
& $T=660-706 \mathrm{~K} ; P=0.07 \mathrm{bar}$ & $\mathrm{He}$ & $4.17 \times 10^{13} e^{-54.10 / R T}$ & Jung et al., 1987 [12] \\
\hline Tubular reactor & $T=800-900 \mathrm{~K} ; P=1 \mathrm{bar}$ & Toluene & $7.3 \times 10^{12} e^{-52.30 / R T}$ & Blades et al. 1952 [13] \\
\hline Shock Tube & $T=740-940 \mathrm{~K} ; 0.7<P<1.7 \mathrm{bar}$ & Ar & $10^{13.19} e^{-53.70 / R T}$ & Tsang et al. 1964 [14] \\
\hline
\end{tabular}

Thomas et al. [11] determined in 1959 in a batch reactor the rate expression of reaction I during the pyrolysis of bromoethane between 653 and $703 \mathrm{~K}$ at 0.48 bar. Later in 1964, Tsang et al. [14] measured again the rate expression of reaction I. Experiments were performed in a shock tube at temperatures between 740 and $940 \mathrm{~K}$ and at pressures between 0.7 and 1.7 bar. Park et al. [16] studied in 1980 the pressure dependence of reaction I. A rise of the pressure from 0.001 bar to 0.076 bar (at 724, 744 and 755 $\mathrm{K}$ ) led to an increase of the value of the rate constant of reaction I by a factor of around 4. Finally, Jung et al. [12] in 1987 studied the kinetics of reaction I using deuterated bromoethanes over the temperature range of $660-706 \mathrm{~K}$ in the presence of $\mathrm{CF}_{4}$ and $\mathrm{He}$ as bath gases at $0.07 \mathrm{bar}$. The pressure dependence of the rate constant was investigated in the fall-off region at three temperatures $(660.2,693.2$, and $706.4 \mathrm{~K})$.

In 2014, Ahubelem et al. [17] theoretically investigated the unimolecular decomposition of selected ethyl halides, including bromoethane, using high level computational chemistry methods. The high pressure limit rate expression has been calculated for temperatures between 300 and $2000 \mathrm{~K}$ as:

$k_{I}=5.7 \times 10^{10} \mathrm{~T}^{1.03} \mathrm{e}^{-54,60 / \mathrm{RT}} \mathrm{s}^{-1}$.

Figure 1 shows the temperature dependence of the rate constants of reaction I determined since 1959. Since the rate constants measured before were all higher by a factor of at least 11 than the more recent 
values, they are not plotted in Figure 1 . In the temperature range $650-700 \mathrm{~K}$, there is an excellent agreement between the expressions measured by Jung et al [12] $(P=0.07$ bar $)$ and Thomas et al. [11] $(P=$ 0.48 bar) and the high pressure limit calculated by Ahubelem et al. [17]. At higher temperatures, the expression measured by Tsang et al. $(0.7<P<1.7$ bar $)$ leads to rate constants for reaction I lower by a factor of 2 than the calculated values.

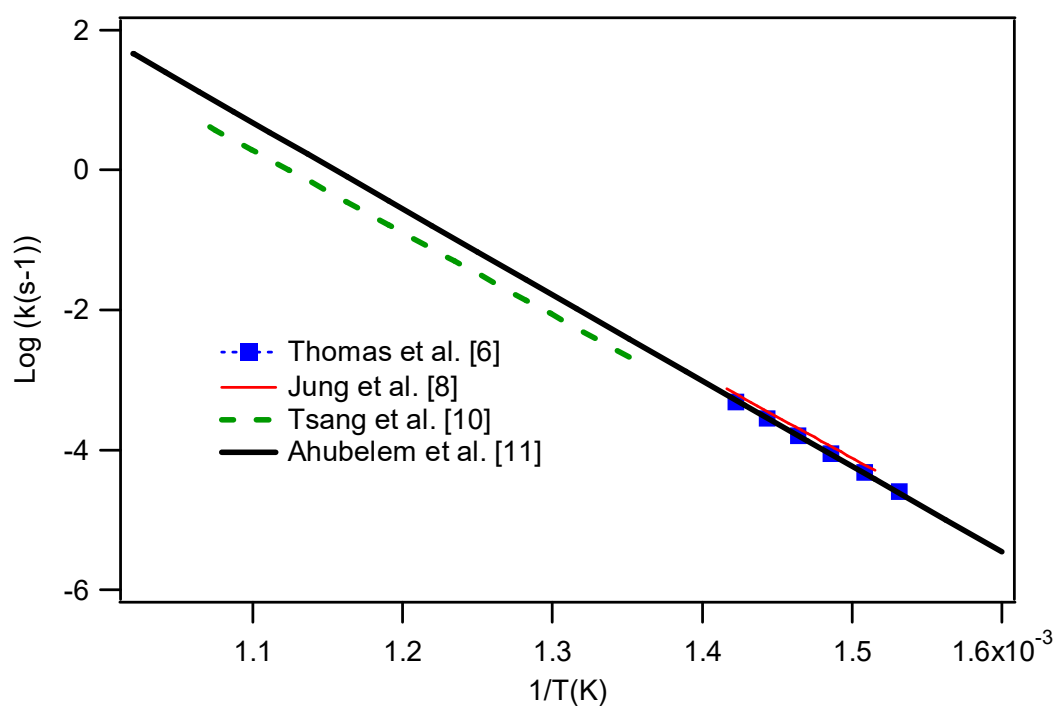

Figure 1: Temperature dependence of the rate constant of reaction I determined since 1959.

The objective of this study is to investigate the bromoethane pyrolysis using two different types of continuous flow reactors, from which reaction products can be easily analyzed, to better understand the chemistry of brominated compounds: a Jet-Stirred Reactor (JSR), which is a type of Continous Stirred Tank Reactor (CSTR) with an homogenous gas phase composition favoring radical reactions, and a Tubular Reactor (TR) which is characterized by a gas phase composition space evolution along the tube. To our knowledge, no previous study of the pyrolysis of bromoethane was performed in a JSR. A new detailed kinetic model has been developed to reproduce these experimental results, using for reaction I the high pressure limit rate expression calculated by Ahubelem et al. [17].

\section{Experimental procedure}

Experiments were carried out in two continuous flow reactors: a jet-stirred-reactor (JSR) and a tubular reactor (TR). In both reactors, species were sampled at the outlet and analyzed using gas chromatography and a Fourier Transform InfraRed (FTIR) spectrometer. The features of the two reactors and analytical 
procedure are described in the following paragraphs. A scheme of the experimental setup and a picture of gas chromatographs are shown in Figures S1 and S2 in SM.

Reactants entered the spherical fused silica JSR (volume of $85 \mathrm{~cm}^{3}$ ) though an injection cross made of four nozzles which was located at its center and created high turbulence to produce homogeneity in composition and temperature of the gas phase [18]. The isothermal JSR is preceded by a quartz annular preheating zone (made of two concentric tubes) in which the temperature of the gas is increased up to the reactor temperature to ensure the temperature homogeneity in the reactor, but also to ensure a good mixing of the inlet mixture. The gas residence time inside the annular preheater is very short compared to its residence time inside the reactor (a few percent). Both the reactor and the preheating zone are heated by the means of Thermocoax resistances rolled up around the reactor. The reaction temperature is measured by a K-type thermocouple located inside the intra-annular space of the preheating zone (the inlet mixture flows in the inter-annular space); its extremity being placed at the level of the injection cross (reaction temperature uncertainty estimated to $\pm 5 \mathrm{~K}$ ). Experiments in the JSR were performed at a constant pressure of 1.067 bar ( 800 Torr), at a residence time of 2 seconds and at temperatures ranging from 600 to $975 \mathrm{~K}$.

Experimental studies in the tubular reactor have been performed using a horizontal $60 \mathrm{~cm}$ long alumina tube (volume of $294 \mathrm{~cm}^{3}$ ) with an inner diameter of $20 \mathrm{~mm}$ and an outer diameter of $25 \mathrm{~mm}$. The ends of the reactor is connected to $2.54 \mathrm{~cm}$ (1-inch) diameter Swagelok unions and sealed with high temperature epoxy resin from Final Crotonics. The tubular reactor is heated by an electrical furnace from Vecstar equipped with an S-type thermocouple. For each set reaction temperature, a temperature profile (temperature versus position in the tubular reactor) in absence of reaction was measured using a R-type thermocouple (see measured profiles in Figure 2). The uncertainty in measured temperatures was estimated to $\pm 5 \mathrm{~K}$. Experiments were performed at a constant pressure of $1.067 \mathrm{bar}$, at a residence time in the set-point temperature zone around 2 seconds and at temperatures ranging from 600 to $975 \mathrm{~K}$.

The two setups used in this study allow the minimization of wall effects which were observed in some former studies [9], [10], [15]. These studies were performed in reactors made of Pyrex which is known for its propensity to catalyze reactions, whereas the jet-stirred reactor used in the present study was made of fused silica and the tubular reactor of alumina. Contrary to previous studies in batch reactors working under low pressure, our setup use continuous flow reactors and work at pressures close to the atmosphere, which also helps minimizing wall effects. 
Simulations were performed assuming that the TR can be modeled as a plug flow reactor and using the measured temperature profiles in absence of reaction.

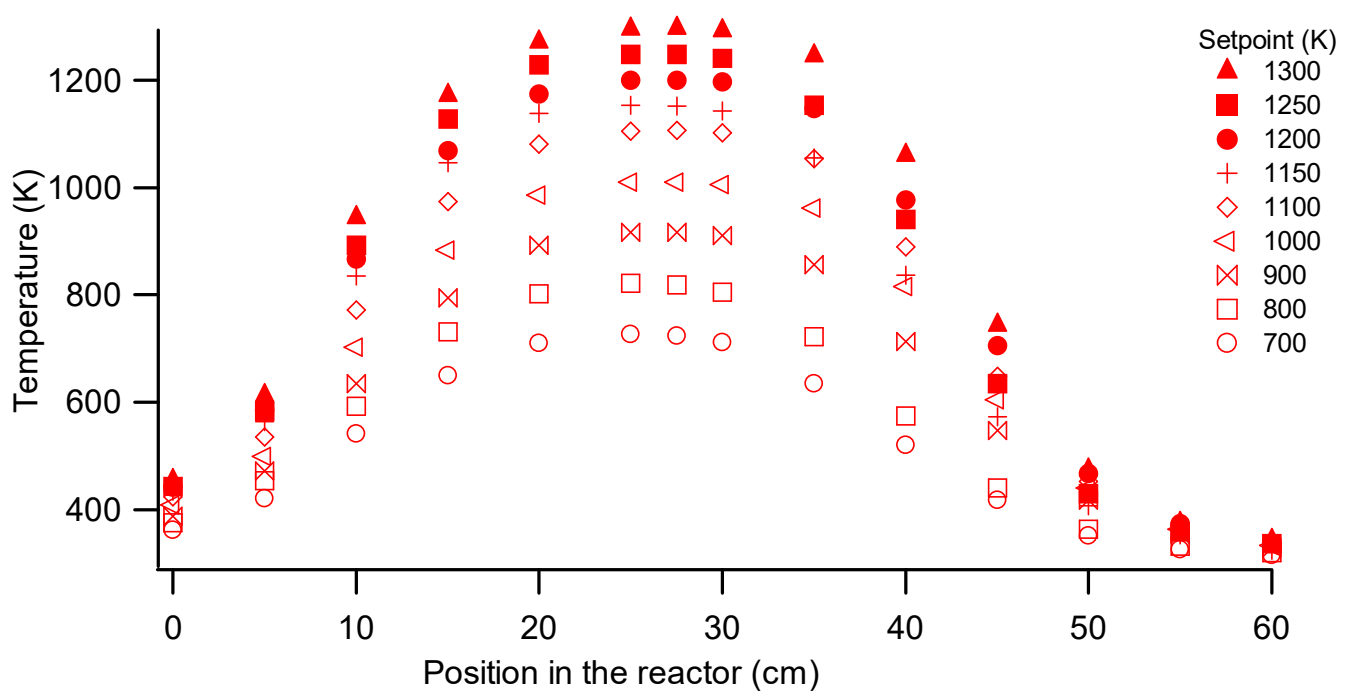

Figure 2: Measured temperature profile in TR in absence of reaction.

Under some temperature and gas flow conditions, a tubular reactor can be considered as a Plug Flow Reactor (PFR). The Peclet criterion, Pe, which compares the effect of axial diffusion and convection phenomena, makes it possible to verify if we can consider an open flow reactor as a PFR. According to Villermaux [19], the results obtained with a tubular reactor are very close to the theoretical results in a PFR when the values of the Peclet number are above 100. The Peclet number is given as follows:

$$
P e=\frac{L^{2}}{D \tau+\frac{Q L}{48 \pi D}}
$$

With $L$ : length of the reactor, $\tau$ : residence time, $D$ : molecular diffusion coefficient, $Q$ : flow rate of the fluid in the reactor.

The values of the Peclet criterion depending on temperature are given in Table 2. In our operating conditions, the Peclet criterion is always above 100 and we can consequently consider our tubular reactor as a Plug Flow Reactor. It is possible to assimilate a plug flow reactor as a cascade of $J$ jet-stirred reactors [20]. To determine this number J, Residence Time Distributions (RTD) were measured in this study by an online mass spectrometer (Omnistar from Pfeiffer) after a pulse injection of argon at the reactor inlet (at 800, 900, 1000 and $1100 \mathrm{~K}$ ). We then performed simulations with MATLAB [21] to determine the number $J$ 
of jet-stirred reactors needed to reproduce the experimental results between 800 and $1100 \mathrm{~K}$. The number $J$ obtained for each temperatures investigated are given in Table 2.

Table 2: Values of the Peclet number, Pe, during the pyrolysis of bromoethane in the TR $(1.0 \%$ bromoethane inlet mole fraction, $P=106.7 \mathrm{kPa}$ ): (a) versus temperature $(T)$ at a residence time (?) of $2 \mathrm{~s}$; (b) versus at at $T=975 \mathrm{~K}$.

(a)

\begin{tabular}{|c|c|c|}
\hline $\boldsymbol{T}(\mathbf{K})$ & $\boldsymbol{P e}$ & $\boldsymbol{J}$ \\
\hline $\mathbf{5 0 0}$ & 410 & $/$ \\
\hline $\mathbf{6 0 0}$ & 341 & $/$ \\
\hline $\mathbf{6 5 0}$ & 315 & $/$ \\
\hline $\mathbf{7 0 0}$ & 293 & $/$ \\
\hline $\mathbf{7 5 0}$ & 273 & $/$ \\
\hline $\mathbf{8 0 0}$ & 256 & 105 \\
\hline $\mathbf{8 5 0}$ & 241 & $/$ \\
\hline $\mathbf{9 0 0}$ & 228 & 75 \\
\hline $\mathbf{9 5 0}$ & 216 & $/$ \\
\hline $\mathbf{1 0 0 0}$ & 205 & 55 \\
\hline $\mathbf{1 0 5 0}$ & 195 & $/$ \\
\hline $\mathbf{1 1 0 0}$ & 187 & 40 \\
\hline $\mathbf{1 2 5 0}$ & 164 & $/$ \\
\hline
\end{tabular}

(b)

\begin{tabular}{|c|c|c|}
\hline $\boldsymbol{\tau}(\mathbf{s})$ & $\boldsymbol{P e}$ & $\boldsymbol{J}$ \\
\hline $\mathbf{2}$ & 211 & 80 \\
\hline $\mathbf{3}$ & 140 & 45 \\
\hline $\mathbf{4}$ & 105 & 35 \\
\hline $\mathbf{5}$ & 84 & 28 \\
\hline $\mathbf{6}$ & 70 & 24 \\
\hline $\mathbf{7}$ & 60 & 19 \\
\hline $\mathbf{8}$ & 52 & 16 \\
\hline
\end{tabular}

As is shown by Figures S5-S8 in Supplementary Material, the higher the temperature or the residence time, the lower $J$, and the lower the ideality of the plug flow reactor. This is in agreement with the data displayed in Table 2 where the Peclet number decreases significantly when the temperature or the residence time increases.

Helium, methane and hydrogen were provided by Messer (purity of $99.999 \%$ ) and the brominated reactant was purchased from Sigma-Aldrich (purity of $98.0 \%$ ). Gas flow rates were controlled by mass flow controllers and the liquid flow rate by a Coriolis flow controller. The uncertainty in the flow measurements was around $0.5 \%$ for each controller, so about $1 \%$ on the residence time.

As described previously [22], using a heated transfer line maintained at $433 \mathrm{~K}$ to avoid product condensation, the gases sampled at the outlet of the reactors were analyzed using: 
- Gas chromatography (GC): methane, ethylene, acetylene and ethane were quantified by a first chromatograph fitted with a PlotQ capillary column, a thermal conductivity detector (TCD) and a flame ionization detector (FID); other types of molecules were quantified using a second chromatograph, fitted with a HP-1 capillary column and a FID. A gas chromatograph equipped with a Plot-Q capillary column and coupled to a mass spectrometer was used to identify the reaction products (mass spectra of the fuel and of species which were not calibrated using standards are given in Figure S4 in SM). Response factors were determined by injecting calibration mixtures or using the effective carbon number method. Relative uncertainties in mole fractions were estimated to be $\pm 5 \%$ for species which were calibrated using standards and $\pm 10 \%$ for other ones. Two typical chromatograms obtained during this study are provided as examples in SM (Figure S3).

- A Fourier Transform InfraRed (FTIR) spectrometry: bromoethane and $\mathrm{HBr}$ were analysed using a FTIR spectrometer from Thermo Scientific Antaris equipped with a Mercure Cadmium Telluride photoelectric detector. FTIR spectroscopy calibrations were obtained by injecting standards and the relative uncertainties in mole fractions were estimated to be $\pm 10 \%$. A typical spectrum recorded using this technique is shown in the results and discussion section of this paper.

\section{Kinetic model}

Simulations were performed using the OpenSmoke package [23] and a newly developed detailed chemical kinetic reaction mechanism for bromoethane pyrolysis including 214 species in 1443 reactions.

The model is based on mechanism proposed by Husson et al. [24] for the oxidation of ethyl-benzene, containing the reactions from $\mathrm{C}_{0}$ to $\mathrm{C}_{8}$ species. Reactions specific to bromoethane have been added to this base mechanism. The mechanism added to the one of Husson et al. [24] is given in Table 3.

In the mechanism of Table 3, the following types of reactions were added to account for the reactant consumption:

- Unimolecular initiation reactions by breaking a C-H, C-C or a C-Br bond (reactions 1 to 4 in Table 3); the $\mathrm{C}-\mathrm{Br}$ bond $\left(70 \mathrm{kcal} / \mathrm{mol}\right.$ [27]) is the weakest one in the bromoethane molecule $\left(\mathrm{C}_{2} \mathrm{H}_{5} \mathrm{Br}\right)$.

- Molecular reactions (reaction 5 to 7), especially reaction I, the decomposition of bromoethane into $\mathrm{HBr}$ and ethylene with the rate expression proposed by Ahubelem et al. [17]. 
Table 3: reactions added to the base mechanism [24] to account for the chemistry of the bromoethane pyrolysis

\begin{tabular}{|c|c|c|c|c|c|}
\hline Reaction & $A$ & $N$ & $E_{a}$ & Footnote & No. \\
\hline \multicolumn{6}{|c|}{ Reactions of bromoethane } \\
\hline \multicolumn{6}{|l|}{ Reactions of unimolecular initiation } \\
\hline $\mathrm{CH}_{3}+\mathrm{CH}_{2} \mathrm{Br}=\mathrm{C}_{2} \mathrm{H}_{5} \mathrm{Br}$ & $3.6 \times 10^{13}$ & 0.0 & 0.0 & $\mathrm{a}$ & (1) \\
\hline $\mathrm{C}_{2} \mathrm{H}_{5}+\mathrm{Br}=\mathrm{C}_{2} \mathrm{H}_{5} \mathrm{Br}$ & $3.6 \times 10^{13}$ & 0.0 & 0.0 & $\mathrm{a}$ & (2) \\
\hline $\mathrm{CH}_{3} \mathrm{CHBr}+\mathrm{H}=\mathrm{C}_{2} \mathrm{H}_{5} \mathrm{Br}$ & $1.0 \times 10^{14}$ & 0.0 & 0.0 & $\mathrm{a}$ & (3) \\
\hline $\mathrm{CH}_{2} \mathrm{CH}_{2} \mathrm{Br}+\mathrm{H}=\mathrm{C}_{2} \mathrm{H}_{5} \mathrm{Br}$ & $1.0 \times 10^{14}$ & 0.0 & 0.0 & $\mathrm{a}$ & (4) \\
\hline \multicolumn{6}{|l|}{ Molecular reactions } \\
\hline $\mathrm{C}_{2} \mathrm{H}_{5} \mathrm{Br}=\mathrm{C}_{2} \mathrm{H}_{4}+\mathrm{HBr}$ & $5.7 \times 10^{10}$ & 1.03 & 54600 & $\mathrm{~b}$ & $(5)$ \\
\hline $\mathrm{CH}_{2} \mathrm{CHBr}=>\mathrm{C}_{2} \mathrm{H}_{2}+\mathrm{HBr}$ & $1.86 \times 10^{12}$ & 3.715 & 63308 & $\mathrm{c}$ & (6) \\
\hline $\mathrm{C}_{2} \mathrm{H}_{2}+\mathrm{HBr}=>\mathrm{CH}_{2} \mathrm{CHBr}$ & $1.422 \times 10^{-2}$ & 4.397 & 34306 & $\mathrm{c}$ & (7) \\
\hline \multicolumn{6}{|l|}{ Reactions of H-atom abstraction } \\
\hline $\mathrm{C}_{2} \mathrm{H}_{5} \mathrm{Br}+\mathrm{H}=>\mathrm{HBr}+\mathrm{C}_{2} \mathrm{H}_{5}$ & $2.94 \times 10^{9}$ & 1.678 & 5594 & $\mathrm{c}$ & (8) \\
\hline $\mathrm{HBr}+\mathrm{C}_{2} \mathrm{H}_{5}=>\mathrm{C}_{2} \mathrm{H}_{5} \mathrm{Br}+\mathrm{H}$ & $1.74 \times 10^{7}$ & 1.889 & 22737 & $\mathrm{c}$ & (9) \\
\hline $\mathrm{C}_{2} \mathrm{H}_{5} \mathrm{Br}+\mathrm{H}=>\mathrm{H}_{2}+\mathrm{CH}_{3} \mathrm{CHBr}$ & $7.18 \times 10^{8}$ & 1.583 & 9555.7 & $\mathrm{c}$ & (10) \\
\hline $\mathrm{H}_{2}+\mathrm{CH}_{3} \mathrm{CHBr}=>\mathrm{C}_{2} \mathrm{H}_{5} \mathrm{Br}+\mathrm{H}$ & $5.94 \times 10^{2}$ & 2.777 & 12191 & $\mathrm{c}$ & (11) \\
\hline $\mathrm{C}_{2} \mathrm{H}_{5} \mathrm{Br}+\mathrm{H}=>\mathrm{H}_{2}+\mathrm{CH}_{2} \mathrm{CH}_{2} \mathrm{Br}$ & $2.24 \times 10^{4}$ & 2.944 & 8477 & $\mathrm{c}$ & (12) \\
\hline $\mathrm{H}_{2}+\mathrm{CH}_{2} \mathrm{CH}_{2} \mathrm{Br}=>\mathrm{C}_{2} \mathrm{H}_{5} \mathrm{Br}+\mathrm{H}$ & $1.0 \times 10^{3}$ & 2.751 & 6760 & $\mathrm{c}$ & (13) \\
\hline $\mathrm{C}_{2} \mathrm{H}_{5} \mathrm{Br}+\mathrm{CH}_{3}=>\mathrm{CH}_{3} \mathrm{Br}+\mathrm{C}_{2} \mathrm{H}_{5}$ & $9.76 \times 10^{6}$ & 1.838 & 15508 & $\mathrm{c}$ & (14) \\
\hline $\mathrm{CH}_{3} \mathrm{Br}+\mathrm{C}_{2} \mathrm{H}_{5}=>\mathrm{C}_{2} \mathrm{H}_{5} \mathrm{Br}+\mathrm{CH}_{3}$ & $2.12 \times 10^{7}$ & 1.967 & 14956 & $\mathrm{c}$ & (15) \\
\hline $\mathrm{C}_{2} \mathrm{H}_{5} \mathrm{Br}+\mathrm{CH}_{3}=>\mathrm{CH}_{4}+\mathrm{CH}_{3} \mathrm{CHBr}$ & $1.52 \times 10^{7}$ & 1.78 & 16797 & $\mathrm{c}$ & (16) \\
\hline $\mathrm{CH}_{4}+\mathrm{CH}_{3} \mathrm{CHBr}=>\mathrm{C}_{2} \mathrm{H}_{5} \mathrm{Br}+\mathrm{CH}_{3}$ & $6.4 \times 10^{6}$ & 1.82 & 21603 & $\mathrm{c}$ & (17) \\
\hline $\mathrm{C}_{2} \mathrm{H}_{5} \mathrm{Br}+\mathrm{CH}_{3}=>\mathrm{CH}_{4}+\mathrm{CH}_{2} \mathrm{CH}_{2} \mathrm{Br}$ & $6.39 \times 10^{7}$ & 1.963 & 16602 & $\mathrm{c}$ & (18) \\
\hline $\mathrm{CH}_{4}+\mathrm{CH}_{2} \mathrm{CH}_{2} \mathrm{Br}=>\mathrm{C}_{2} \mathrm{H}_{5} \mathrm{Br}+\mathrm{CH}_{3}$ & $8.12 \times 10^{7}$ & 1.901 & 20456 & $\mathrm{c}$ & (19) \\
\hline $\mathrm{C}_{2} \mathrm{H}_{5} \mathrm{Br}+\mathrm{C}_{2} \mathrm{H}_{5}=\mathrm{C}_{2} \mathrm{H}_{6}+\mathrm{CH}_{3} \mathrm{CHBr}$ & $1.87 \times 10^{-4}$ & 5.05 & 7880 & $\mathrm{~d}$ & (20) \\
\hline $\mathrm{C}_{2} \mathrm{H}_{6}+\mathrm{CH}_{3} \mathrm{CHBr}=>\mathrm{C}_{2} \mathrm{H}_{5} \mathrm{Br}+\mathrm{C}_{2} \mathrm{H}_{5}$ & $4.48 \times 10^{-5}$ & 5.29 & 15658 & $\mathrm{~d}$ & (21) \\
\hline $\mathrm{C}_{2} \mathrm{H}_{5} \mathrm{Br}+\mathrm{C}_{2} \mathrm{H}_{5}=>\mathrm{C}_{2} \mathrm{H}_{6}+\mathrm{CH}_{2} \mathrm{CH}_{2} \mathrm{Br}$ & $3.33 \times 10^{4}$ & 3.1 & 13544 & $d$ & $(22)$ \\
\hline $\mathrm{C}_{2} \mathrm{H}_{6}+\mathrm{CH}_{2} \mathrm{CH}_{2} \mathrm{Br}=>\mathrm{C}_{2} \mathrm{H}_{5} \mathrm{Br}+\mathrm{C}_{2} \mathrm{H}_{5}$ & $1.77 \times 10^{4}$ & 3.2 & 16796 & $\mathrm{~d}$ & (23) \\
\hline $\mathrm{C}_{2} \mathrm{H}_{5} \mathrm{Br}+\mathrm{Br}=\mathrm{Br}_{2}+\mathrm{C}_{2} \mathrm{H}_{5}$ & $0.15 \times 10^{13}$ & 0.0 & 20800 & $\mathrm{c}$ & (24) \\
\hline $\mathrm{C}_{2} \mathrm{H}_{5} \mathrm{Br}+\mathrm{Br}=>\mathrm{HBr}+\mathrm{CH}_{2} \mathrm{CH}_{2} \mathrm{Br}$ & $0.36 \times 10^{6}$ & 2.73 & 9983 & $\mathrm{c}$ & $(25)$ \\
\hline $\mathrm{HBr}+\mathrm{CH}_{2} \mathrm{CH}_{2} \mathrm{Br}=>\mathrm{C}_{2} \mathrm{H}_{5} \mathrm{Br}+\mathrm{Br}$ & $0.71 \times 10^{3}$ & 2.69 & -4036 & $\mathrm{c}$ & (26) \\
\hline $\mathrm{C}_{2} \mathrm{H}_{5} \mathrm{Br}+\mathrm{Br}=\mathrm{HBr}+\mathrm{CH}_{3} \mathrm{CHBr}$ & $0.58 \times 10^{13}$ & 0.26 & 13700 & $\mathrm{c}$ & (27) \\
\hline \multicolumn{6}{|l|}{ Reactions of $\beta$-scission } \\
\hline $\mathrm{CH}_{2} \mathrm{CH}_{2} \mathrm{Br}=\mathrm{C}_{2} \mathrm{H}_{4}+\mathrm{Br}$ & $0.58 \times 10^{13}$ & 0.26 & 13700 & $\mathrm{c}$ & $(28)$ \\
\hline $\mathrm{CH}_{2} \mathrm{CH}_{2} \mathrm{Br}=\mathrm{CH}_{2} \mathrm{CHBr}+\mathrm{H}$ & $9.94 \times 10^{13}$ & -0.039 & 42704 & $\mathrm{c}$ & (29) \\
\hline $\mathrm{CH}_{2} \mathrm{CHBr}+\mathrm{H}=\mathrm{CH}_{2} \mathrm{CH}_{2} \mathrm{Br}$ & $1.96 \times 10^{8}$ & 1.89 & 2853 & $\mathrm{c}$ & (30) \\
\hline $\mathrm{CH}_{3} \mathrm{CHBr}=\mathrm{CH}_{2} \mathrm{CHBr}+\mathrm{H}$ & $3.39 \times 10^{8}$ & 1.70 & 36648 & $\mathrm{c}$ & (31) \\
\hline $\mathrm{CH}_{2} \mathrm{CHBr}+\mathrm{H}=\mathrm{CH}_{3} \mathrm{CHBr}$ & $1.72 \times 10^{8}$ & 2.06 & 50.7 & $\mathrm{c}$ & (32) \\
\hline \multicolumn{6}{|l|}{ Reactions of termination } \\
\hline $\mathrm{H}+\mathrm{Br}=\mathrm{HBr}$ & $2.90 \times 10^{16}$ & -1.5 & 0.0 & $\mathrm{e}$ & (33) \\
\hline $\mathrm{Br}+\mathrm{Br}=\mathrm{Br}_{2}$ & $1.48 \times 10^{14}$ & 0.0 & -1701 & $\mathrm{f}$ & $(34)$ \\
\hline $\begin{array}{l}\text { Note: The rate constants are given in the fo } \\
\text { units of cal/mol. } \\
\text { a Rate constants estimated by analogy with } \\
\text { b Rate constants taken equal to the values } \\
\text { c Rate constants calculated using quantum } \\
\text { d Rate constants estimated by analogy with } \\
\text { e Rate constants taken equal to the values } \\
\text { f Rate constants taken equal to the values }\end{array}$ & $\begin{array}{l}\text { RT) where } A \text { he } \\
\text { alkanes with th } \\
\text { m et al. [17]. } \\
\text { traction on br } \\
\text { l et al. [25]. } \\
\text { al. [26]. }\end{array}$ & $\begin{array}{l}\text { its of } \mathrm{cm}^{3} \\
\text { tware EX }\end{array}$ & $\begin{array}{l}\text { ol, s, } T \text { ha } \\
\text { S. }\end{array}$ & ts of $\mathrm{K}$, and & ias \\
\hline
\end{tabular}


- The $\mathrm{H}$-atom abstraction reactions by $\mathrm{H}$-atoms (reactions 9 to 13), by $\mathrm{Br}$-atoms (reactions 24 to 27), by methyl radicals (reactions 15 to 19) and by ethyl radical (reactions 20 to 23) with reverse reactions.

- Br-atom abstraction reactions by H-atoms (reaction 8) and methyl radical (reaction 14).

- Reactions of $\beta$-scission of the $\mathrm{CH}_{2} \mathrm{CH}_{2} \mathrm{Br}$ and $\mathrm{CH}_{3} \mathrm{CHBr}$ radicals (reactions 28 to 32).

- Reactions of termination yielding $\mathrm{HBr}$ and $\mathrm{Br}_{2}$ (reactions 32 to 34).

When possible, calculations using quantum methods were carried out for kinetic constants when no data were available using the Gaussian 09 revision B.01 suite of programs [28] (at CBS-QB3 level [29]). The conformational analysis was performed to check that optimized structures well corresponded to global minima (at the B3LYP/6-31G(d) level [30]). Internal rotations of moieties around simple bonds in optimized species have been treated like hindered rotors and their contribution were considered in kinetic parameter calculations through the calculation of partition functions. Intrinsic reaction coordinate calculations were performed to check that transitions states well connected both reactants and products. Kinetic constants were calculated thanks the transition state theory using Gibbs energies of species involved in the considered reaction. They were corrected to take into account the tunneling (using the asymmetric Eckart potential). The gpop software suite from Miyoshi [31] was used to perform the posttreatment of the Gaussian calculations. Comparisons were made with literature data when available for rate constant calculation strategy assessment (Figures S9 and S10). An excellent agreement was obtained between the rate constants calculated by Ahubelem et al. [13] and that calculated in this work for the molecular reaction of decomposition of bromoethane to ethylene and $\mathrm{HBr}$ (Figure S9). This is not surprising given that calculations were performed using a similar strategy at the same level (CBS-QB3). Overall the agreement is good with other literature data. A good agreement was also obtained for the reaction of $\mathrm{Br}$-atom abstraction from bromoethane to $\mathrm{HBr}$ and the ethyl radical (Figure S10). To our knowledge, there are no other data in literature available for comparisons.

The thermodynamic data were taken from the database of Burcat et al. [32] or calculated by the Thergas software [33] based on group additivity method.

\section{Results and discussion}

This part presents the main results obtained during the pyrolysis of bromoethane in the JSR and the TR. It also displays the comparison with data computed using the detailed kinetic model developed in this study. A kinetic study of the model is then performed to highlight the specificities of the chemistry of the pyrolysis of bromoethane. 


\subsection{Bromoethane conversion}

Figure 3 presents experimental and simulated evolutions with temperature of bromoethane conversion obtained in the jet-stirred reactor (JSR) and in the tubular reactor (TR) under the same operating conditions.
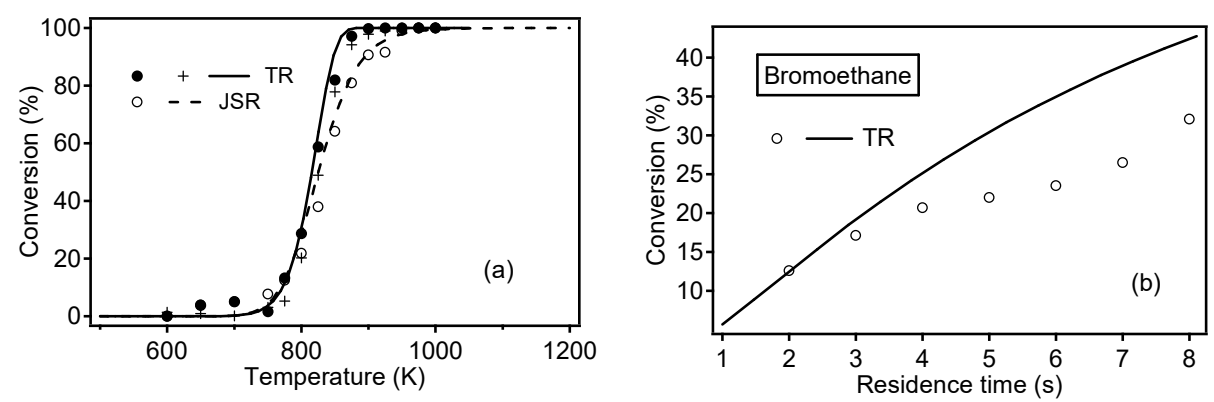

Figure 3: Evolution of bromoethane conversion with (a) temperature in both reactors, (b) residence

time in the tubular reactor (TR) (Symbols are experiments and lines simulations, $775 \mathrm{~K}, 1 \%$ bromoethane inlet mole fraction, $\tau=2 \mathrm{~s}, P=1.067 \mathrm{bar}$ ). Circles are GC measurements, crosses are FTIR ones

Figure 3 (a) shows that the molecule starts to be consumed at $600 \mathrm{~K}$ in both reactors. Furthermore, the type of reactor has an influence on bromoethane conversion. Indeed, the reactivity is larger in the TR than in the JSR (full conversion at $925 \mathrm{~K}$ in the TR and at $975 \mathrm{~K}$ in the JSR). This is in line with the theory of ideal reactors since it can be shown that, for a simple reaction $\mathrm{A} \rightarrow$ products, the conversion in a plug flow is larger than in a perfectly stirred reactor, under equal operating operations [20]. The model predicts well the evolution of bromoethane conversion with temperature in both reactors.

Figure 3 (b) shows that a rise of the residence time from 2 to 8 seconds leads to an increase of the conversion from 12.6 to $32.1 \%$. The model is in agreement with the experimental results for small residence times (between 2 and 4 seconds) but overestimates the conversion for the highest residence times. The fact that a larger deviation between simulation and experiments was observed when residence time increases is in agreement with the fact that the PRF is less ideal as is shown by the smaller Peclet numbers and $J$ (Table 2).

\subsection{Product formation}

This part presents the experimental and computed results for the products obtained during the pyrolysis of bromoethane in both reactors. Since $\mathrm{HBr}$ has been measured during the experiments in TR, it is clear now 
that the major products during the pyrolysis of bromoethane are $\mathrm{HBr}$ and ethylene in both reactors. This highlights the importance of the molecular reaction (reaction I) and confirms the results of the previously listed studies

\subsubsection{JSR product formation}

Figure 4 presents the experimental and simulated evolution with temperature of the mole fractions of ethylene, vinyl bromide, ethane, acetylene, 1,3-butadiene, methane and vinyl acetylene measured in the JSR.
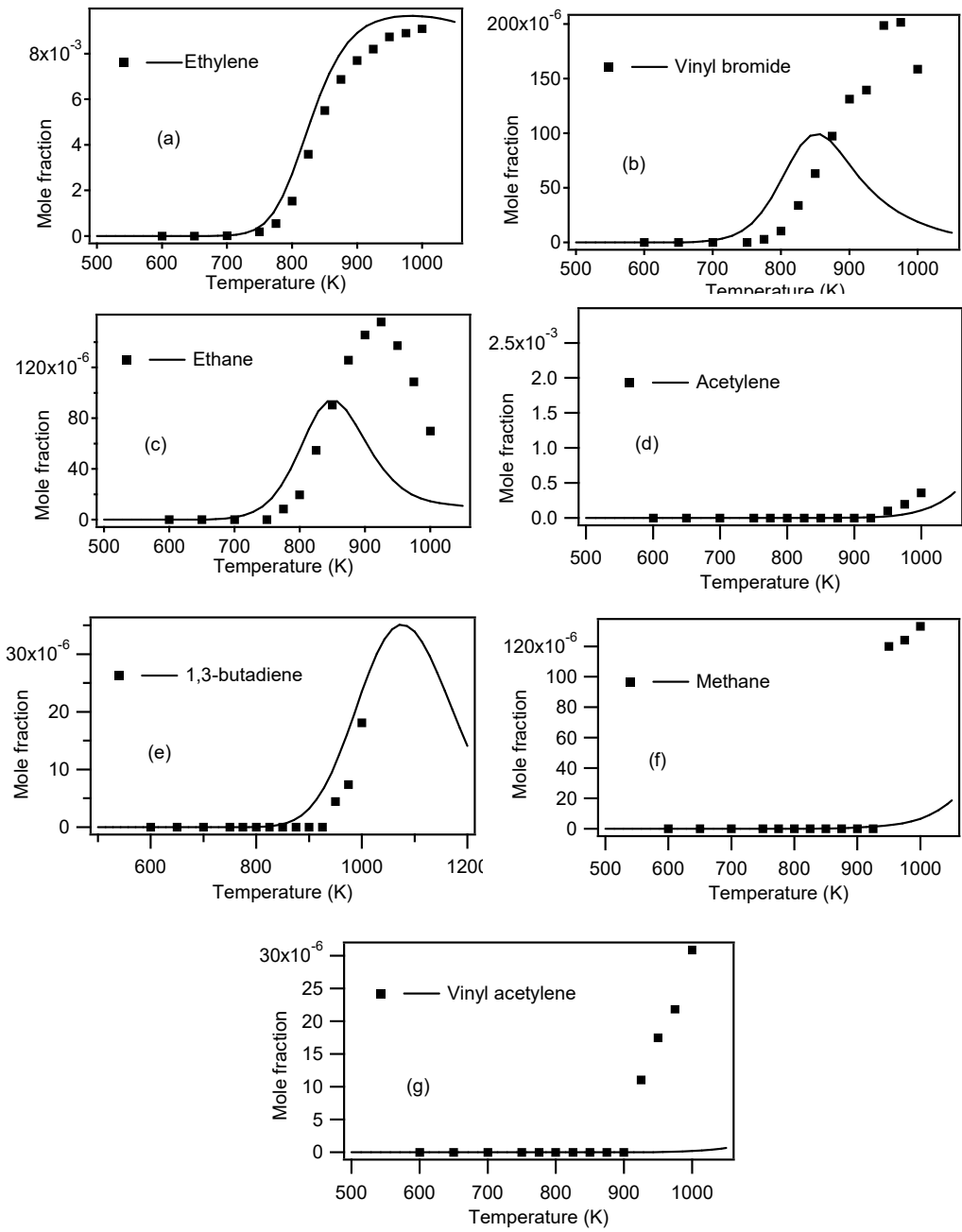

Figure 4: JSR mole fraction evolution with temperature of (a) ethylene (b) vinyl bromide, (c) ethane (d) acetylene (e) 1,3-butadiene (f) methane (g) vinyl acetylene with $1.0 \%$ bromoethane inlet mole fraction at $\tau=2 \mathrm{~s}$ and $P=1.067 \mathrm{bar}$. Symbols are experiments and lines simulations. 
The kinetic model predicts well the formation of ethylene and 1,3-butadiene. The formations of ethane and vinyl bromide are well predicted at low temperatures (between 700 and $850 \mathrm{~K}$ ) and overestimated at higher temperatures. Methane and vinylacetylene formations are underestimated whatever the temperature.

Figure 4 shows that ethylene is by far the major product identified, even if $\mathrm{HBr}$ has not been measured during the experiments in the JSR.

\subsubsection{TR product formation}

$\mathrm{HBr}$ has been quantified in the TR using FTIR spectroscopy. To determine its mole fraction, an hypothesis has been made: supposing that all the main bromine species have been quantified, the mole fraction of $\mathrm{HBr}$ can be determined by using the bromine balance during the pyrolysis of bromoethane for each temperatures.

Figure 5 gives an infrared spectrum measured by FTIR at $825 \mathrm{~K}$ during the pyrolysis of bromoethane. The reactant and the 2 main products ( $\mathrm{HBr}$ and ethylene) are well visible on the spectrum.

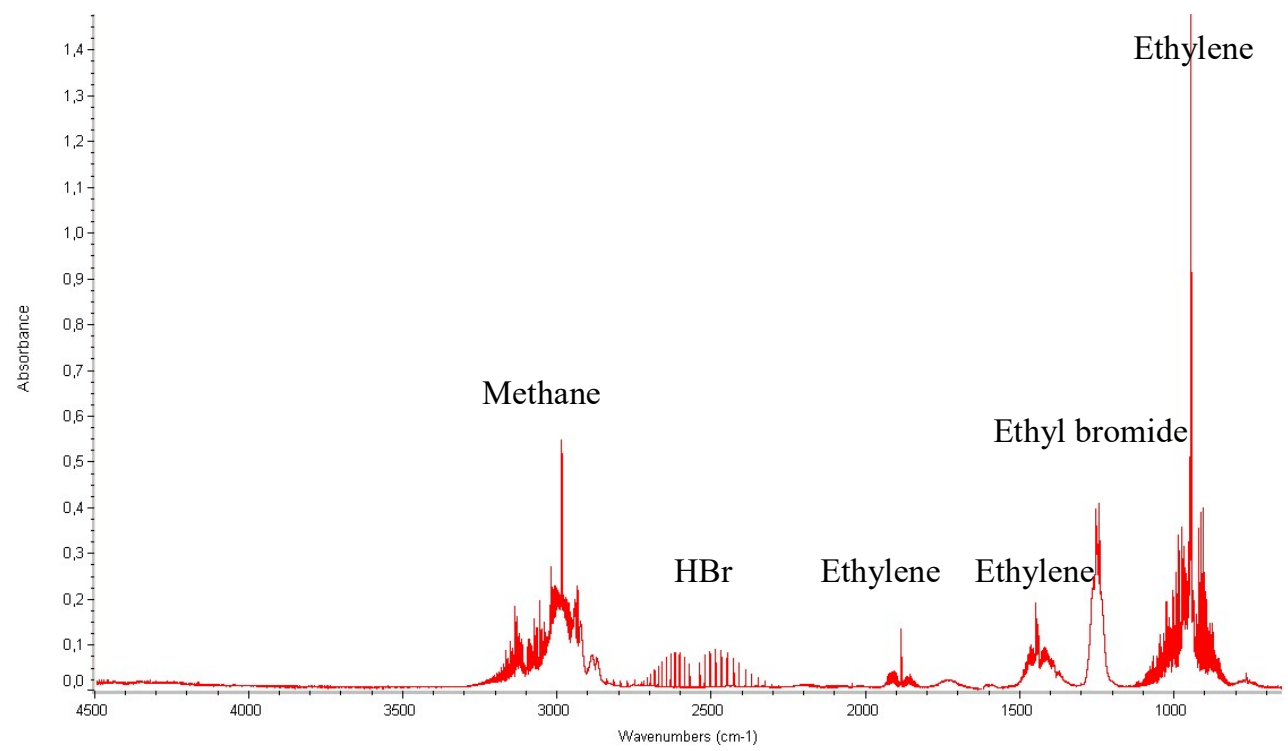

Figure 5: Infrared spectrum obtained by FTIR spectroscopy during the pyrolysis of bromoethane in the tubular reactor ( $825 \mathrm{~K}, 1.0 \%$ bromoethane inlet mole fraction at $\tau=2 \mathrm{~s}$ and $\boldsymbol{P}=1.067 \mathrm{bar}$ ). 

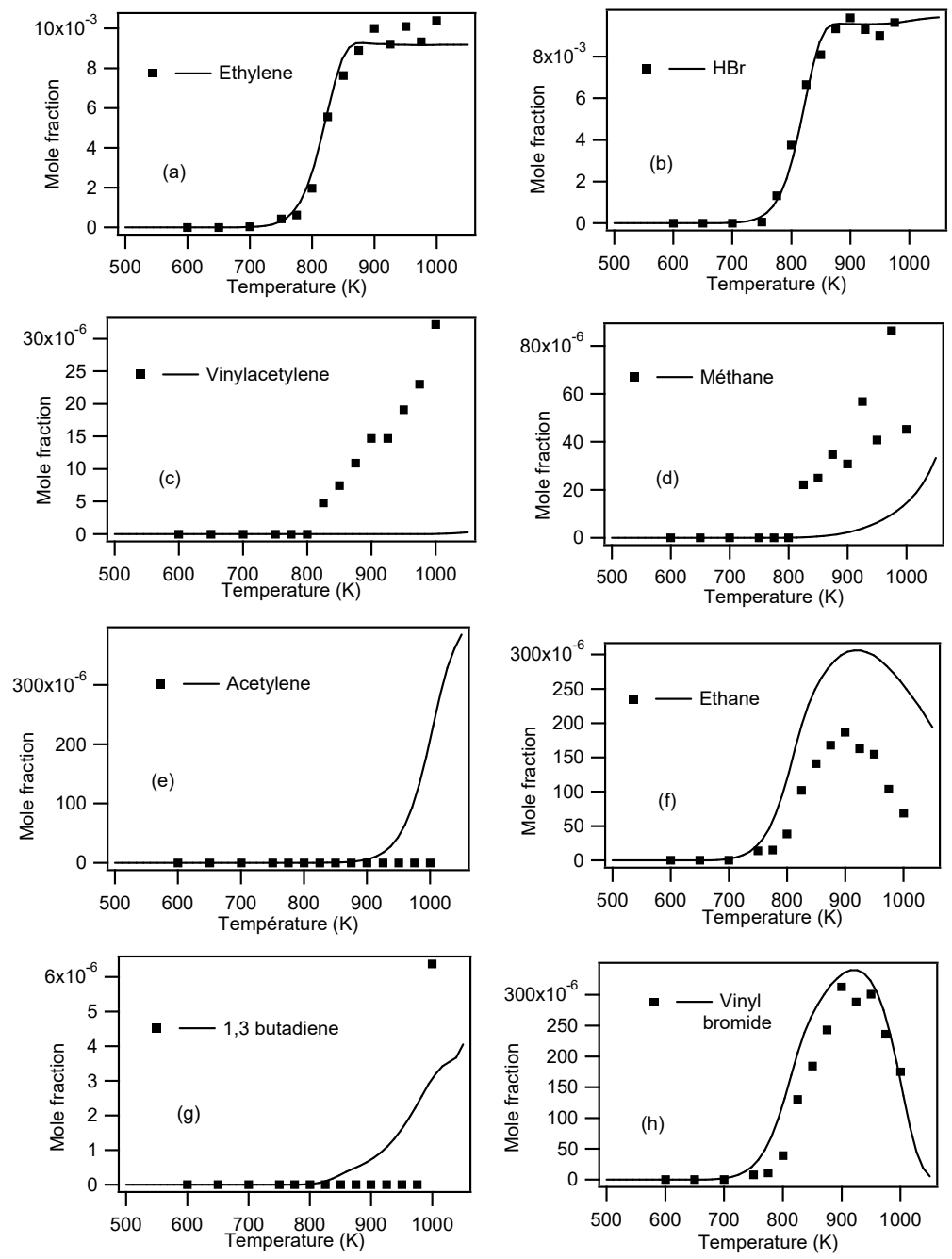

Figure 6: JSR mole fraction evolution with temperature of (a) ethylene (b) $\mathrm{HBr}$ (c) vinyl acetylene (d) methane (e) acetylene (f) ethane (g) 1,3-butadiene (h) vinyl bromide with $1.0 \%$ bromoethane inlet mole fraction at $\tau=2 \mathrm{~s}$ and $P=1.067 \mathrm{bar}$. Symbols are experiments and lines simulations. $\mathrm{HBr}$

\section{has been quantified by FTIR}

Figure 6 shows experimental and simulated mole fractions of ethylene, $\mathrm{HBr}$, vinyl acetylene, methane, acetylene, ethane, 1,3-butadiene, and vinyl bromide as a function of temperature during the pyrolysis of bromoethane in the TR. The model predicts very well the formation of ethylene, $\mathrm{HBr}$ and vinyl bromide. Ethane and acetylene formation are overestimated whereas methane and vinyl acetylene mole fractions are underestimated. 


\subsection{Discussion}

In previous studies Blades et al. [13] postulated that the reaction of decomposition of bromoethane is intramolecular as well as Thomas et al. [11]. However, Daniels et al. [9] have detected small amounts of hydrogen, ethane, propane, butane (in addition to ethylene) in decreasing amount of abundance. They specify in their paper that the dissociation of bromoethane into ethyl radical and Br-atom is possible and propose three different mechanisms and two of them are radical mechanisms. Goldberg et al. [10] also reported that the thermal decomposition of bromoethane cannot be explained by a simple molecular reaction. The large variety of detected reaction products detected in the present study confirms that the radical mechanism does exist and is very important under operating conditions used in experiments. Furthermore, the formation of vinyl bromide as well as vinyl acetylene and 1,3-butadiene has been detected for the first time during this study under our operating conditions. Modeling efforts were made in the present study to develop the first detailed kinetic model for the pyrolysis of bromoethane. This model was used to run kinetic analyses and better understand the chemistry of the pyrolysis of bromoethane.

Figure 7 shows the carbon selectivity product obtained during bromoethane pyrolysis in both reactors. At approximately the same conversion, the carbon product selectivity seems to be quite similar even if more methane, vinyl bromide and ethane are produced in the TR than in the JSR. Ethylene is by far the major carbon containing reaction product (its selectivity is divided by 10 in Figure 7). The formation of $\mathrm{Br}_{2}$ was not observed during this study although this species can be detected with the thermal conductivity detector of the gas chromatograph used in this study. This is likely due to concentrations below the detection limit. This is in agreement with data computed using the detailed kinetic model (maximum concentration of $8,6 \mathrm{ppm}$ at $1016 \mathrm{~K}$ in the tubular reactor). No dibrominated aliphatic compounds were detected in these experiments. $\mathrm{HBr}$ and vinyl bromide are the only brominated products observed during this study. The bromine atom balance (comparing the $\mathrm{Br}$ atom number in $\mathrm{HBr}$, vinyl bromide and unreacted bromoethane against that in bromoethane at the inlet of the reactor) was performed in the tubular reactor and is satisfactory. It oscillates around $100 \%$ with a standard deviation of $\pm 4,8 \%$ over the whole temperature range, similarly to the carbon atom balance (see Tables S1-S2 in supplementary material). 


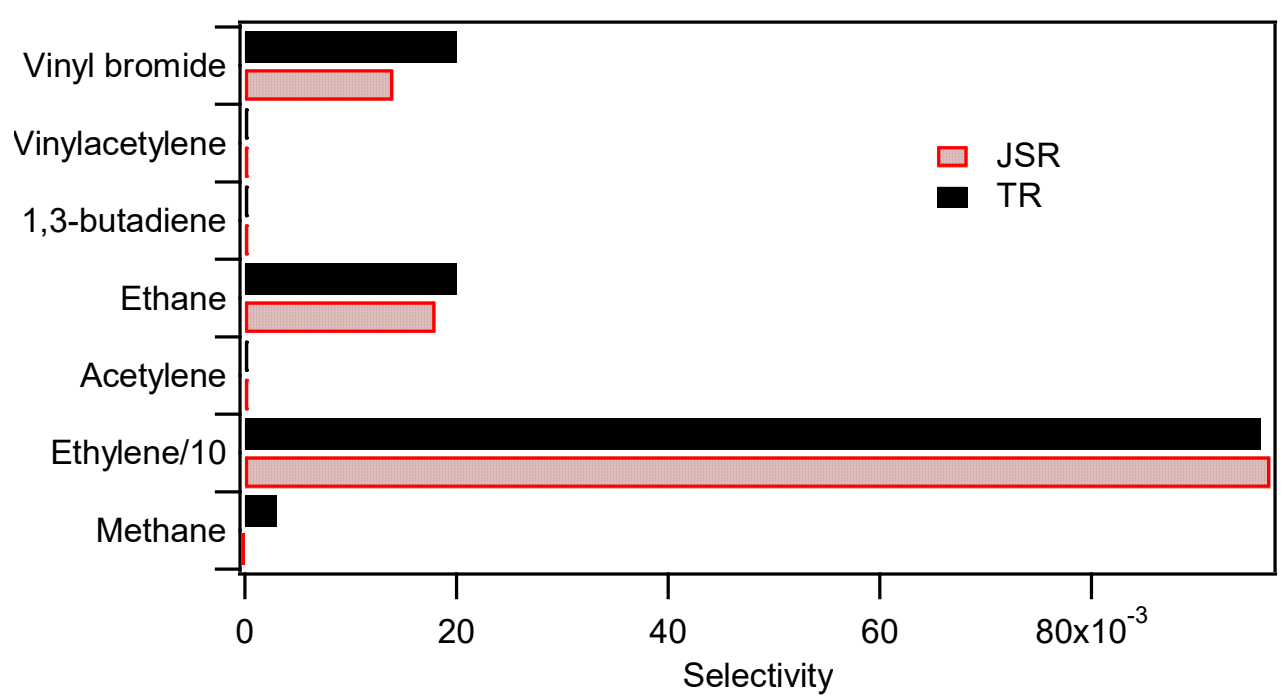

Figure 7: Carbon atom containing product selectivity obtained during bromoethane pyrolysis in the TR (850 K, $1.0 \%$ bromoethane inlet mole fraction, $\tau=2 \mathrm{~s}, P=1.067 \mathrm{bar}, 81.9 \%$ conversion) and in the JSR (875 K, $1.0 \%$ bromoethane inlet mole fraction, $\tau=2 \mathrm{~s}, P=1.067 \mathrm{bar}, 82.8 \%$ conversion).

As the model reproduces in an acceptable way the JSR and the TR experimental results, Figure 8 presents a flow rate analysis performed at $833 \mathrm{~K}$ using the OpenSmoke package [23] during the pyrolysis of bromoethane in JSR. The major consumption pathways of bromoethane decomposition are:

- Reaction I, by molecular reaction giving ethylene and $\operatorname{HBr}(43.0 \%)$.

- by $\mathrm{H}$-atom abstraction with bromine atoms (51.3\%) producing $\mathrm{HBr}$ and the bromoethane radical $\left(\mathrm{CH}_{2} \mathrm{CH}_{2} \mathrm{Br}\right)$.

Reaction I is then not the only pathway to be considered during bromoethane thermal decomposition, it is not even the most important one under the conditions of this study. The sequence of reactions composed of the fuel $\mathrm{H}$-atom abstraction by bromine atoms forming $\mathrm{CH}_{2} \mathrm{CH}_{2} \mathrm{Br}$ and the reaction of decomposition by ?scission of $\mathrm{CH}_{2} \mathrm{CH}_{2} \mathrm{Br}$ to ethylene and $\mathrm{HBr}$ forms a propagation loop (sequence of reaction consuming a radical in the first step and regenerating this radical in the last step) which is characteristic of straight chain radical mechanisms. These propagation loops are responsible for the large reactivity of organic compounds during gas phase pyrolysis reactions. At $833 \mathrm{~K}$, the overall rate of consumption of bromoethane though this propagation loop is about 320 times larger than the rate of consumption of bromoethane though the breaking of $\mathrm{C}-\mathrm{Br}$ bond which is the weakest bond in the fuel $\left(70.0 \mathrm{kcal}^{\mathrm{mol}}{ }^{-1}\right.$ [27]).

The flow rate analysis also confirms that bromine atoms mainly react with the fuel by reactions of $\mathrm{H}$-atom abstraction (leading to the formation of $\mathrm{HBr}$ ) rather than by reactions of termination and addition. This is in agreement with the non-detection of $\mathrm{Br}_{2}$ and dibrominated compounds during experiments. 


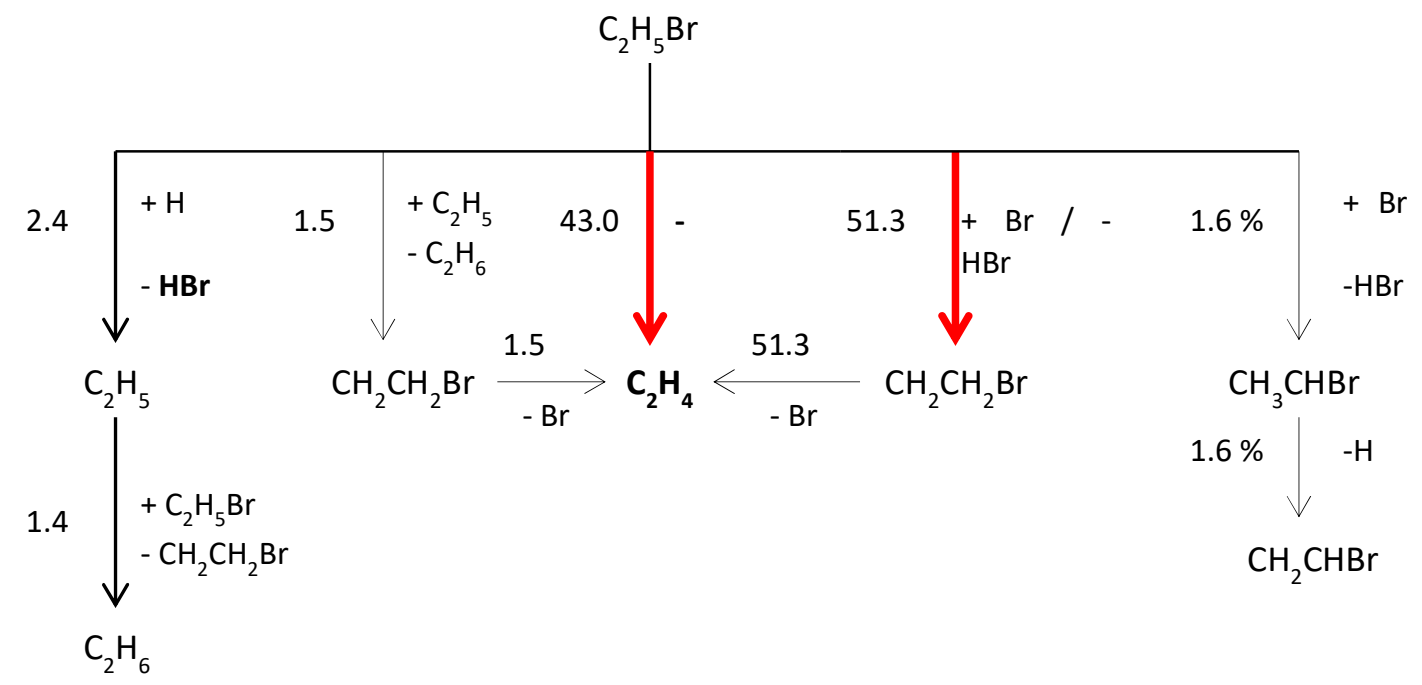

Figure 8: Flow rate analysis at $833 \mathrm{~K}(0.01$ bromoethane inlet mole fraction, $\tau=2 \mathrm{~s}, P=1.067 \mathrm{bar})$.

Numbers on arrows represent the consumption rates normalized by the total bromoethane consumption rate. Red thick arrows correspond to the main ways of decomposition of bromoethane.

Minor consumption pathways (less than $2.4 \%$ each) include the $\mathrm{H}$-atom abstraction with bromine atoms leading to the other bromoethane radical $\left(\mathrm{CH}_{3} \mathrm{CHBr}\right)$ and $\mathrm{HBr}(1.6 \%)$, the $\mathrm{H}$-atom abstraction with ethyl radical giving $\mathrm{CH}_{2} \mathrm{CH}_{2} \mathrm{Br}$ and ethane $(1.5 \%)$ and the $\mathrm{H}$-atom abstraction with hydrogen radical producing ethyl radical and $\mathrm{HBr}(2.4 \%)$. The $\beta$-scission of the $\mathrm{CH}_{3} \mathrm{CHBr}$ radical leads to the formation of vinyl bromide $\left(\mathrm{CH}_{2} \mathrm{CHBr}\right)$.

To better understand the most influential reactions, a sensitivity analysis at $833 \mathrm{~K}$ was performed. It is shown in Figure 9.

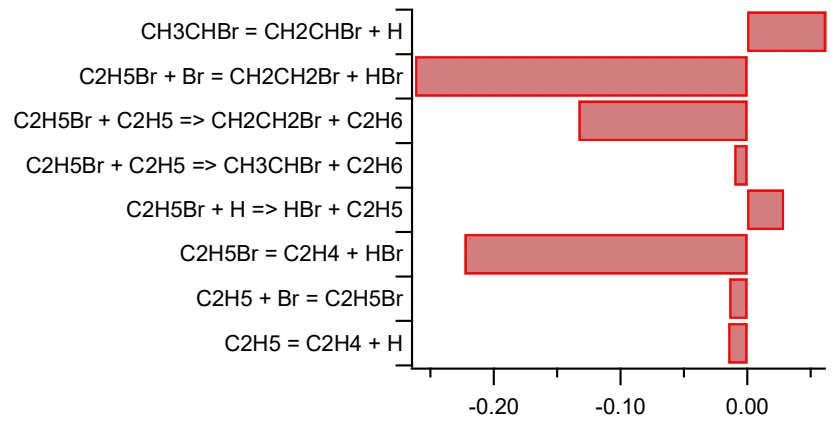

Figure 9: Sensitivity analysis on bromoethane mole fraction at $833 \mathrm{~K}(0.01$ bromoethane inlet mole fraction, $\tau=2 \mathrm{~s}, P=1.067 \mathrm{bar}$ ). Reactions with a negative coefficient have a promoting effect on the reactivity. 
The reactions with the largest promoting effect at $833 \mathrm{~K}$ are (by decreasing importance):

- The H-atom abstraction with the bromine atom giving $\mathrm{CH}_{2} \mathrm{CH}_{2} \mathrm{Br}$ and $\mathrm{HBr}$

- The molecular reaction (reaction I) leading to the two main products: ethylene and $\mathrm{HBr}$.

- The H-atom abstraction with ethyl radical producing the reactant radical and ethane

This brings to light the fact that, in addition to the molecular reaction, the $\mathrm{H}$-atom abstraction with the bromine atom (producing $\mathrm{CH}_{2} \mathrm{CH}_{2} \mathrm{Br}$ ) is also important. The radical mechanism is thus far from being negligible compared to the molecular decomposition pathway. The sole analysis of reaction product can be misleading as the radical mechanism mainly leads to the same products (ethylene and $\mathrm{HBr}$ ) as the molecular decomposition reaction of bromoethane (reaction I).

However, the radical $\mathrm{CH}_{3} \mathrm{CHBr}$ decomposition to create vinyl bromide has an inhibiting effect as well as the Br-atom abstraction with hydrogen radical on bromoethane leading to $\mathrm{HBr}$ and ethyl radical.

\section{Conclusion}

A study of bromoethane pyrolysis has been carried out in two different reactors: a jet-stirred reactor and a tubular reactor. Temperatures ranged from 600 to $975 \mathrm{~K}$. The residence time was in both reactors equal to $2 \mathrm{~s}$ with a bromoethane inlet mole fraction of 0.01 (dilution in helium). All experiments were performed at a pressure of 1.067 bar. The following products were identified: ethylene, $\mathrm{HBr}$, vinyl bromide, methane, ethane, acetylene, 1,3-butadiene, vinyl acetylene. $\mathrm{HBr}$ could be quantified during the experiments in the TR thanks the use of FTIR spectroscopy. As in previous literature studies, ethylene and HBr were detected as the major reaction products. The numerous minor products detected in this study show that the molecular decomposition of bromoethane to ethylene and $\mathrm{HBr}$ is not the only consumption pathway and that the radical mechanism play an important role under the studied conditions. This confirms the conclusion made in previous literature studies by Daniels et al. [9] and Goldberg et al. [10].

Since there is a lack of kinetic data in the literature about brominated compounds, a detailed kinetic model has been developed based on theoretically calculated rate parameters. This model gives satisfactory predictions of the reactivity and formation of major compounds ( $\mathrm{HBr}$, ethylene) in both reactors. Ethane and vinyl bromide profiles are better predicted by the kinetic model in the TR than in the JSR. Model refinements are needed to better account for the formation of minor products. This will require the experimental studies of these intermediates to better understand their pyrolysis chemistry. 
The kinetic analysis performed using the detailed kinetic model developed in this study showed that there are two major decomposition pathways of bromoethane: the molecular reaction giving ethylene and $\mathrm{HBr}$, and the $\mathrm{H}$-atom abstraction by bromine atom on the bromoethane producing $\mathrm{CH}_{2} \mathrm{CH}_{2} \mathrm{Br}$ and $\mathrm{HBr}$, with quasi equal importance. This observation could not be deduced from the sole interpretation of experimental results as the two pathways produce the same reaction products. It confirms that the radical mechanism plays an important role in the thermal decomposition of bromoethane in the conditions of the present study.

\section{Acknowledgements}

This work has been supported by TERBIS, 943 rue Pasteur, 60700 Pont Sainte Maxence, France.

\section{References}

[1] P. R. S. Kodavanti, T. E. Stoker, and S. E. Fenton, 'Chapter 38 - Brominated Flame Retardants', in Reproductive and Developmental Toxicology (Second Edition), R. C. Gupta, Ed. Academic Press, 2017, pp. 681-710.

[2] S. D. Shaw, J. H. Harris, M. L. Berger, B. Subedi, and K. Kannan, 'Brominated Flame Retardants and Their Replacements in Food Packaging and Household Products: Uses, Human Exposure, and Health Effects', in Toxicants in Food Packaging and Household Plastics: Exposure and Health Risks to Consumers, S. M. Snedeker, Ed. London: Springer London, 2014, pp. 61-93.

[3] C. Ma et al., 'Chemical recycling of brominated flame retarded plastics from e-waste for clean fuels production: A review', Renew. Sustain. Energy Rev., vol. 61, pp. 433-450, Aug. 2016.

[4] M. Zhang, A. Buekens, and X. Li, 'Brominated flame retardants and the formation of dioxins and furans in fires and combustion', J. Hazard. Mater., vol. 304, pp. 26-39, Mar. 2016.

[5] H. Jungk, C. R. Smoot, and H. C. Brown, 'Kinetics of Methylation and Ethylation of Benzene and Toluene in 1,2,4-Trichlorobenzene under the Influence of Aluminum Bromide; Mechanism of the Alkylation Reaction1,2', J. Am. Chem. Soc., vol. 78, no. 10, pp. 2185-2190, May 1956.

[6] R. W. D. Taylor, 'Methyl bromide-Is there any future for this noteworthy fumigant?', J. Stored Prod. Res., vol. 30, no. 4, pp. 253-260, Oct. 1994.

[7] E. T. Lessig, 'The Decomposition of Ethyl Bromide, Alkyl Halides, and Acetal in the Gas Phase at $300^{\circ}-$ $400^{\circ}$, J. Phys. Chem., vol. 36, no. 8, pp. 2325-2337, Jan. 1931.

[8] E. L. Vernon and F. Daniels, 'Kinetics of the Unimolecular Dissociation of Gaseous Ethyl Bromide1', J. Am. Chem. Soc., vol. 55, no. 3, pp. 922-934, Mar. 1933.

[9] F. Daniels and P. L. Veltman, 'The Decomposition of Ethyl Bromide and the Collision Theory of First-Order Reactions', J. Chem. Phys., vol. 7, no. 9, pp. 756-766, Sep. 1939. 
[10] A. E. Goldberg and F. Daniels, 'Kinetics of the Pyrolysis of Ethyl Bromide1', J. Am. Chem. Soc., vol. 79, no. 6, pp. 1314-1320, Mar. 1957.

[11] P. J. Thomas, '234. Studies in the pyrolysis of organic bromides. Part XII. The unimolecular decompositions of ethyl bromide and 4-bromopent-1-ene', J. Chem. Soc. Resumed, vol. 0, no. 0, pp. 1192-1196, Jan. 1959.

[12] K.-H. Jung, S. H. Kang, C. U. Ro, and E. Tschuikow-Roux, 'Collisional energy transfer in the two-channel thermal unimolecular reaction of bromoethane-2-d', vol. 91, 1987.

[13] A. T. Blades and G. W. Murphy, 'The Kinetics of the Decompositions of Ethyl, Isopropyl and n-Propyl Bromides', J. Am. Chem. Soc., vol. 74, no. 24, pp. 6219-6221, Dec. 1952.

[14] W. Tsang, 'Thermal Decomposition of Some Alkyl Halides by a Shock-Tube Method', J. Chem. Phys., vol. 41, no. 8, pp. 2487-2494, Oct. 1964.

[15] P. Fugassi and F. Daniels, 'A Study of the Decomposition of Gaseous Ethyl Bromide', J. Am. Chem. Soc., vol. 60, no. 4, pp. 771-778, Apr. 1938.

[16] T. J. Park and K. H. Jung, 'Thermal unimolecular decomposition reactions of ethyl bromide at 724.5755.1ํ'ㄴ, vol. 1, pp. 30-35, 1980.

[17] N. Ahubelem, M. Altarawneh, and B. Z. Dlugogorski, 'Dehydrohalogenation of ethyl halides', Tetrahedron Lett., vol. 55, no. 35, pp. 4860-4868, Aug. 2014.

[18] R. David and D. Matras, 'Règies de construction et d'extrapolation des réacteurs auto-agités par jets gazeux', Can. J. Chem. Eng., vol. 53, no. 3, pp. 297-300, Jun. 1975.

[19] J. VILLERMAUX, 'Réacteurs chimiques - Principes', Ref: TIP452WEB - 'Opérations unitaires. Génie de la réaction chimique', 10-Mar-1994. [Online]. Available: https://www.techniques-ingenieur.fr/basedocumentaire/procedes-chimie-bio-agro-th2/reacteurs-chimiques-42330210/reacteurs-chimiquesj4010/. [Accessed: 24-Jan-2018].

[20] O. Levenspiel, 'Chemical Reaction Engineering', Ind. Eng. Chem. Res., vol. 38, no. 11, pp. 4140-4143, Nov. 1999.

[21] The MathWorks, Inc. and Natick, MATLAB and Statistics Toolbox Release. Massachusetts, United States.

[22] N. Vin et al., 'A study of chlorobenzene pyrolysis', Proc. Combust. Inst., Jun. 2018.

[23] A. Cuoci, A. Frassoldati, T. Faravelli, and E. Ranzi, 'OpenSMOKE++: An object-oriented framework for the numerical modeling of reactive systems with detailed kinetic mechanisms', Comput. Phys. Commun., vol. 192, pp. 237-264, Jul. 2015.

[24] B. Husson, M. Ferrari, O. Herbinet, S. S. Ahmed, P.-A. Glaude, and F. Battin-Leclerc, 'New experimental evidence and modeling study of the ethylbenzene oxidation', Proc. Combust. Inst., vol. 34, no. 1, pp. 325-333, Jan. 2013. 
[25] E. S. Campbell and R. M. Fristrom, 'Reaction Kinetics, Thermodynamics, And Transport In The Hydrogen-Bromine System - A Survey Of Properties For Flame Studies', Chem. Rev., vol. 58, no. 2, pp. 173-234, Apr. 1958.

[26] D. L. Baulch, J. Duxbury, S. J. Grant, and D. C. Montague, 'Evaluated Kinetic Data for High Temperature Reactions. Volume 4. Homogeneous Gas Phase Reactions of Halogen- and Cyanide-Containing Species', National Standart Reference Data System, Jan. 1981.

[27] Y.-R. Luo, Comprehensive Handbook of Chemical Bond Energies. CRC Press, 2007.

[28] M. J. Frisch et al., Gaussian 09. Wallingford CT, 2010.

[29] J. A. Montgomery, M. J. Frisch, J. W. Ochterski, and G. A. Petersson, 'A complete basis set model chemistry. VI. Use of density functional geometries and frequencies', J. Chem. Phys., vol. 110, no. 6, pp. 2822-2827, Jan. 1999.

[30] A. D. Becke, 'Density-functional thermochemistry. III. The role of exact exchange', J. Chem. Phys., vol. 98, no. 7, pp. 5648-5652, Apr. 1993.

[31] A. Miyoshi, GPOP. .

[32] A. Burcat, 'Third Millennium Ideal Gas and Condensed Phase Thermochemical Database for Combustion with Updates from Active Thermochemical Tables'.

[33] C. Muller, V. Michel, G. Scacchi, and G. M. Côme, "THERGAS: a computer program for the evaluation of thermochemical data of molecules and free radicals in the gas phase', J. Chim. Phys., vol. 92, pp. 11541178, 1995. 